\title{
La Revista de la Academia, un ícono en el desarrollo de la ciencia en Colombia
}

La producción de conocimiento autóctono es la base del desarrollo de una nación. Colombia es un país excepcional por su inmensa diversidad cultural, geográfica y de recursos naturales. ¡Cuántos países del mundo quisieran tener al menos parte de esas riquezas! Costas en dos océanos, tres cordilleras, llanos orientales, amazonia, Chocó biogeográfico, La Guajira. Esa diversidad de ambientes alberga una gran multiplicidad de culturas. Pero, así mismo, genera una serie de retos que requieren del análisis cuidadoso de expertos que puedan proponer acciones apropiadas para enfrentarlos. Elemento fundamental en la comprensión de nuestra nacionalidad lo constituye el estudio concienzudo de su historia. El país debe aprender a valorizar su desarrollo histórico y todo lo que este representa. Al lado de su historia, su cultura, sus riquezas, y también - en parte - como resultado de su diversidad, el país enfrenta problemas en el ámbito de la salud, de la educación, del agro y del clima, entre otros.

Desde su creación hace ochenta años, mediante el decreto 1218 del 28 de mayo de 1936, la Academia Colombiana de Ciencias Exactas, Físicas y Naturales ha contribuido en forma notable al desarrollo de una cultura científica nacional y, en términos generales, a analizar y proponer alternativas frente a la realidad de un país profundamente complejo e increíblemente fascinante. Los aportes de sus miembros en sus respectivas áreas del saber han propiciado el crecimiento y el fortalecimiento de una ciencia que hasta comienzos del siglo XX era incipiente. Cinco de sus seis primeros presidentes eran ingenieros con intereses en asuntos tales como la astronomía o las matemáticas. Solamente el padre Jesús Emilio Ramírez, sacerdote jesuita, se apartó de esa tendencia, pues sus estudios superiores los realizó en Geofísica. El padre Ramírez fue uno de los creadores del Instituto Geofísico en la Pontificia Universidad Javeriana.

La vida de la Academia ha estado acompañada desde sus comienzos por la Revista de la Academia Colombiana de Ciencias Exactas, Físicas y Naturales. En efecto, en el último trimestre de 1936 apareció su primer número bajo la dirección del ingeniero Jorge Álvarez Lleras, quien para entonces también fungía como primer Presidente de la Academia. En su nota editorial, el ingeniero Álvarez Lleras se refirió a la revista como el "órgano de propaganda científica y cultural" de la Academia. En la primera mitad del siglo XX los medios de comunicación científica eran limitadísimos, de tal manera que la Revista de la Academia vino a cubrir ese vacío. Sin duda alguna, la Academia contaba entre sus miembros con los más importantes exponentes de la comunidad científica de la época, lo que aseguraba la excelente calidad de los trabajos que serían publicados.

Además del ingeniero Jorge Álvarez Lleras, quien fuera el editor de la revista de 1936 a 1950, han ocupado este cargo los Académicos Belisario Ruiz Wilches (1950-1956), Luis María Murillo (1957-1961), Luis Duque Gómez, (1962-1970), Gustavo Perry Zubieta (1972-1980), Luis Eduardo Mora Osejo (1981), Julio Carrizosa Umaña (1982-1989), Santiago Díaz Piedrahita (1989-2006); Pedro Prieto (2006 a junio de 2010), Margarita Perea Dallos (septiembre de 2010 a junio de 2013), John D. Lynch (septiembre a diciembre de 2013), Carmenza Duque y Elizabeth Castañeda (marzo a diciembre de 2014), Elizabeth Castañeda (marzo de 2015 hasta la fecha). El Académico Román Castañeda fue editor del suplemento especial dedicado al Año Internacional de la Luz en 2015.

Desde sus inicios, la Revista de la Academia Colombiana de Ciencias Exactas, Físicas y Naturales ha sido una publicación periódica, multidisciplinaria, que tiene como objetivo dar a conocer artículos de investigación inéditos de alta calidad. El primer número de la Revista ya dejaba vislumbrar la amplia cobertura de los asuntos que han sido tratados por sus autores a lo largo de estos ochenta años de existencia. Allí aparecen trabajos sobre zoología, climatología, salud, sanidad vegetal, astronomía, matemáticas y geografía. Una hojeada a un número tomado al azar (vol. XXXIII, No. 126, marzo de 2009) muestra, de nuevo, la variedad y el alcance de los temas estudiados: botánica y conservación, ciencias de la tierra, genética humana, historia y filosofía de la ciencia, matemáticas, química y zoología.

Durante los últimos tres años (2013 - 2016) la Revista ha sufrido transformaciones sustanciales de forma y de fondo. En la actualidad, por ejemplo, solamente se publica en formato electrónico, y los manuscritos presentados para posible publicación, así como los apartes de la revista misma, se clasifican en las siguientes áreas: ciencias físicas (física, físicoquímica, materiales); ciencias naturales (biología, botánica, zoología, ecología, bioquímica); ciencias de la tierra (geología, medio ambiente); ciencias humanas o ciencias del comportamiento (filosofía, sicología, antropología, sociología); ciencias biomédicas, matemáticas y ciencias químicas. En 2015 y 2016 se seleccionaron imágenes temáticas para la carátula que incluyeron un homenaje a la Real Expedición Botánica del Nuevo Reino de Granada, al Académico de Número Santiago Díaz Piedrahita - fallecido recientemente -, y a Francisco José de Caldas con motivo del bicentenario de su fallecimiento (29 de octubre de 1816 - 29 de octubre de 2016). 
El 2017 será el año de celebración de los ochenta años de la Revista; su editora y el comité editorial han ideado y puesto en marcha diversas formas de enriquecer esa conmemoración. Para comenzar, el número de diciembre de 2016 presenta en su carátula la reproducción de la carátula del primer número de la Revista. Asi mismo, se seleccionarán y reproducirán trabajos que han sido publicados en la revista y que se han convertido en verdaderos clásicos de la literatura científica colombiana y universal, prácticamente en todas las áreas.

La Academia Colombiana de Ciencias Exactas, Físicas y Naturales continúa comprometida con la tarea de hacer conocer a través de su Revista la producción científica colombiana e internacional del más alto nivel, bajo el liderazgo de la editora y con el concurso de un selecto consejo editorial y de numerosos evaluadores que, en forma desinteresada, colaboran con ese importante aspecto de la vida de toda revista de carácter científico y académico.

El aniversario número ochenta de la Revista de la Academia se convierte en un estímulo y en un reto para todos los miembros de la institución. Es responsabilidad de todos velar por que esta publicación continúe llenando las expectativas de la comunidad científica nacional y mundial.

En mi condición de Presidente de la Academia Colombiana de Ciencias Exactas, Físicas y Naturales, expreso un sincero reconocimiento a la editora, a su cuerpo de asesoras (asistente editorial, correctora de estilo, diagramadora), y a todos quienes han contribuido con el arduo trabajo de preparación y publicación de la Revista, cuya financiación es posible gracias a los aportes del Gobierno Nacional a través del Ministerio de Educación Nacional.

\section{Enrique Forero}

Presidente

Academia Colombiana de Ciencias

Exactas, Físicas y Naturales 